\title{
STEEL PLANT MODEL FOR SOLVING LOGISTIC BOTTLENECKS WITH ADVANCED PLANT SIMULATION*
}

\author{
Frank Schrama ${ }^{1}$ \\ Daan Merkenstein ${ }^{2}$ \\ Mart Jansen ${ }^{3}$ \\ Walter Vortrefflich ${ }^{4}$ \\ Bart van den Berg ${ }^{5}$
}

\begin{abstract}
The Steel Plant Model (SPM) is an advanced logistic simulation model for steel plants. With the SPM, bottlenecks can be solved and logistics can be optimized. Both existing plants and greenfield designs can be simulated. All movements and actions simulated, from hot metal to cast products. Not only all major equipment and their relevant components (like a sublance) are simulated, but also ladles, scrap boxes, transfer cars and cranes. The whole plant is simulated in 3D and actual distances and speeds determine transport times. The SPM includes process time deviations and equipment downtimes for maintenance or unexpected breakdowns. This ensures more realistic and reliable results. Logistic optimization is based on comparison of different scenarios. For a new scenario, equipment and practices, etc. can easily be modified, added or removed. At the same time the SPM produces all relevant data for every new scenario, which can be presented conveniently. This makes the SPM the ultimate tool to find bottlenecks or optimize plant logistics. The SPM is validated for several plants world-wide, with different characteristics and layouts. The SPM not only realistically simulates existing plants with all utilizations, crane movements and waiting times, but also to accurately predicts the influence of plant modifications or unexpected events like breakdowns. Given the flexibility of the SPM, any (new) steel plant can be simulated quickly when a layout and the requested data are provided.
\end{abstract}

Keywords: Logistic model; Simulation; Steel plant design; Bottleneck.

Process engineer, Danieli Corus, Velsen-Noord, the Netherlands.

Simulation engineer, Systems Navigator, Delft, the Netherlands.

Project manager, Systems Navigator, Delft, the Netherlands.

Executive vice president, Danieli Linz, Linz, Austria.

Senior process engineer, Danieli Corus, Velsen-Noord, the Netherlands. 


\section{INTRODUCTION}

Steel plant logistics are an important, but often underestimated part of steelmaking at an industrial level. Since the 19th century engineers are using static calculations and rules of thumb to analyze steel plant logistics. Even though these calculations were based on many years of experience, they could never really take the unexpected (process time deviations, cranes with two jobs at the same time or failures) into account. This reduced the reliability and even the value of these static calculations. In 2011 metal industry engineering company Danieli Corus (Velsen-Noord, the Netherlands) together with software consultancy company Systems Navigator (Delft, the Netherlands) decided to develop an advanced logistic simulation model as a better alternative to solve logistic issues of steel plants. The Steel Plant Model (SPM) should become the ultimate tool for process engineers to get a new and better insight in steel plant logistics.

In 2013 the SPM was validated for the first time for a steel plant in Europe. In 2014 the Tata Steel plant in Port Talbot (United Kingdom) was simulated in order to analyze logistic issues, compare possible solutions and quantify the results. That year SPM simulations were also used for the improvement of an existing Indian steel plant. In September 2014 the SPM was presented publically at the European Oxygen Steelmaking Conference (EOSC) in Trinec, Czech Republic [1]. Since 2014 the SPM is used to support Danieli in several greenfield steel plant designs in India, Russia and China.

\section{MODEL DESCRIPTION}

The SPM consists of a Human Machine Interface (HMI) and the actual model. The model itself is object orientated and is built in a $3 \mathrm{D}$ environment. The HMI runs in the program Scenario Navigator. In Scenario Navigator all input for the SPM can be given and when the simulation of a scenario is finished the output is presented in a clear and orderly way [2].

In the SPM the entire steel plant is simulated in 3D from the hot metal bay to the casting bay (Figure 1). For the calculations the model uses the actual sizes, distances and velocities. Every major object in the steel plant (e.g. equipment, ladles and cranes) is simulated, including its process times, movements, velocity, maintenance and unexpected breakdowns. The model can also take probability distributions of various process parameters (like process times) into account. Furthermore, all objects in the model communicate with each other. Due to these qualities the SPM is an advanced model that simulates a steel plant very realistically, sensitively and accurately. 

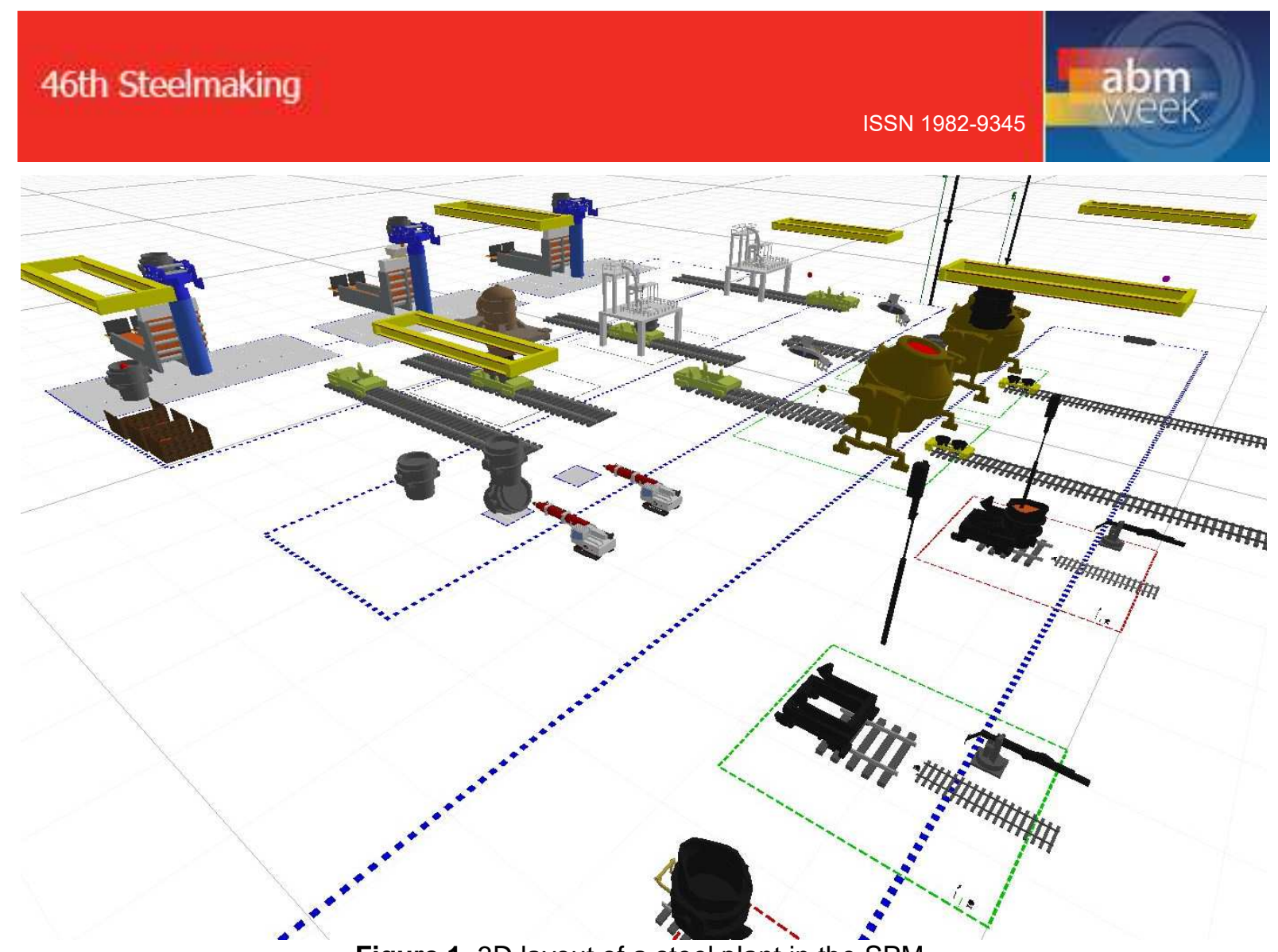

Figure 1. 3D layout of a steel plant in the SPM.

The simulation of a steel plant in the object orientated model is done chronologically. Based on production schedules heats are requested in series of a certain steel grade, which are then assigned to a caster. The heats are created at the plant entrance as hot metal in a torpedo or ladle. A heat will follow the process steps according to its steel grade. When for a certain process step more than one option exists (for example two different ladle furnaces; which can have similar or different properties), the model will choose the best option based on availability and priority. The heat leaves the simulated plant when it is casted.

The transportation of ladles and scrap boxes by cranes and transfer cars is all simulated in the SPM, instead of reducing transportation to a simple time delay. This includes the simulation of crane and car limitations (like being unable to pass or being occupied). The so called Smart Cranes in the SPM are, based on priorities, timing and situation, able to take over each other's job or move another crane aside. In the field of steel plant simulation, the SPM is unique in simulating transportation at this high level of detail.

The SPM proves to be able to predict steel production and equipment utilizations for a given period for any steel plant. Furthermore the SPM provides a wide range of production data varying from annual plant production figures to data at the level of a single object (including cranes and ladles) or heat. This information includes utilization, capacity, idle times, maintenance, and task breakdowns.

Thanks to the 3D setup of the SPM, a running simulation can be followed real time (or accelerated) from every possible angle or viewpoint. It is also possible to simply walk through the plant. This enables an engineer to detect and visualize logistic problems in the steel plant very easily. 


\section{CASE STUDY}

\subsection{Introduction}

To give an insight in the capabilities of the SPM, what the approach of a problem is and what the results of a simulation can be, a case study of a fictive steel plant is described here. Although the SPM has far more options than can be described here, this case study should give a good indication of the SPM's capabilities.

The steel plant contains the following major equipment:

- 2 Hot metal pits (HMP)

- 2 Hot metal desulphurization stations (HMD)

- 2 Converters (BOF)

- 2 Ladle furnaces (LF)

- 1 Vacuum degasser (VD)

- $\quad 2$ Continuous casting machines (CCM)

- 1 Ladle treatment station (TS)

The plant's layout has three separate bays, with two multifunctional cranes in each bay. The crane logic is programmed following Danieli Corus experience, combined with knowledge of Danieli Linz. The heat size is $160 \mathrm{t}$ and there are 2 active hot metal ladles and 9 active steel ladles.

Table 1 shows the average process times of all major equipment $(\mu)$, as well as their standard deviations $(\sigma)$. In this case it is assumed that all process times are normal distributed. Absolute minimum processing times are added to avoid non-realistic situations. No difference between the process times for the different steel grades is assumed. Since the caster can adjust its speed based on availability of steel (these casters can slow down to $66.7 \%$ of their original speed; this is called starving), its process time is the minimum time it would cost to cast a full steel ladle at maximum speed. If the starving does not help and the series break, the total net restart time of the caster (including ramping up for the first slab) is 45 minutes.

Table 1. Process times and standard deviations of major equipment.

\begin{tabular}{lcc}
\hline & $\boldsymbol{\mu}[\mathbf{m i n}]$ & $\boldsymbol{\sigma}[\mathbf{m i n}]$ \\
\hline HMD & 30 & 2.25 \\
\hline BOF & 36 & 1.25 \\
\hline LF & 32 & 1.25 \\
\hline VD & 27 & 1.75 \\
\hline CCM & 45 & - \\
\hline
\end{tabular}

\subsection{Base case and Validation}

The steel plant is built in 3D in the model and all parameters, routings, crane movements and priorities are implemented (only the most important parameters are mentioned in this article). Figure 2 shows a layout overview of this plant. With this layout (the third, future CCM does not participate yet) the base case scenario is run. This base case scenario mirrors the steel plants practice over the whole simulation time period. The results of this scenario are used to identify bottlenecks and analyze the equipment/crane utilizations and ladle empty/full times. In the case of an existing plant the results of this scenario are compared with the actual data, in order to validate the model (in addition extra scenarios of known cases are run as well for further validation of the model). 


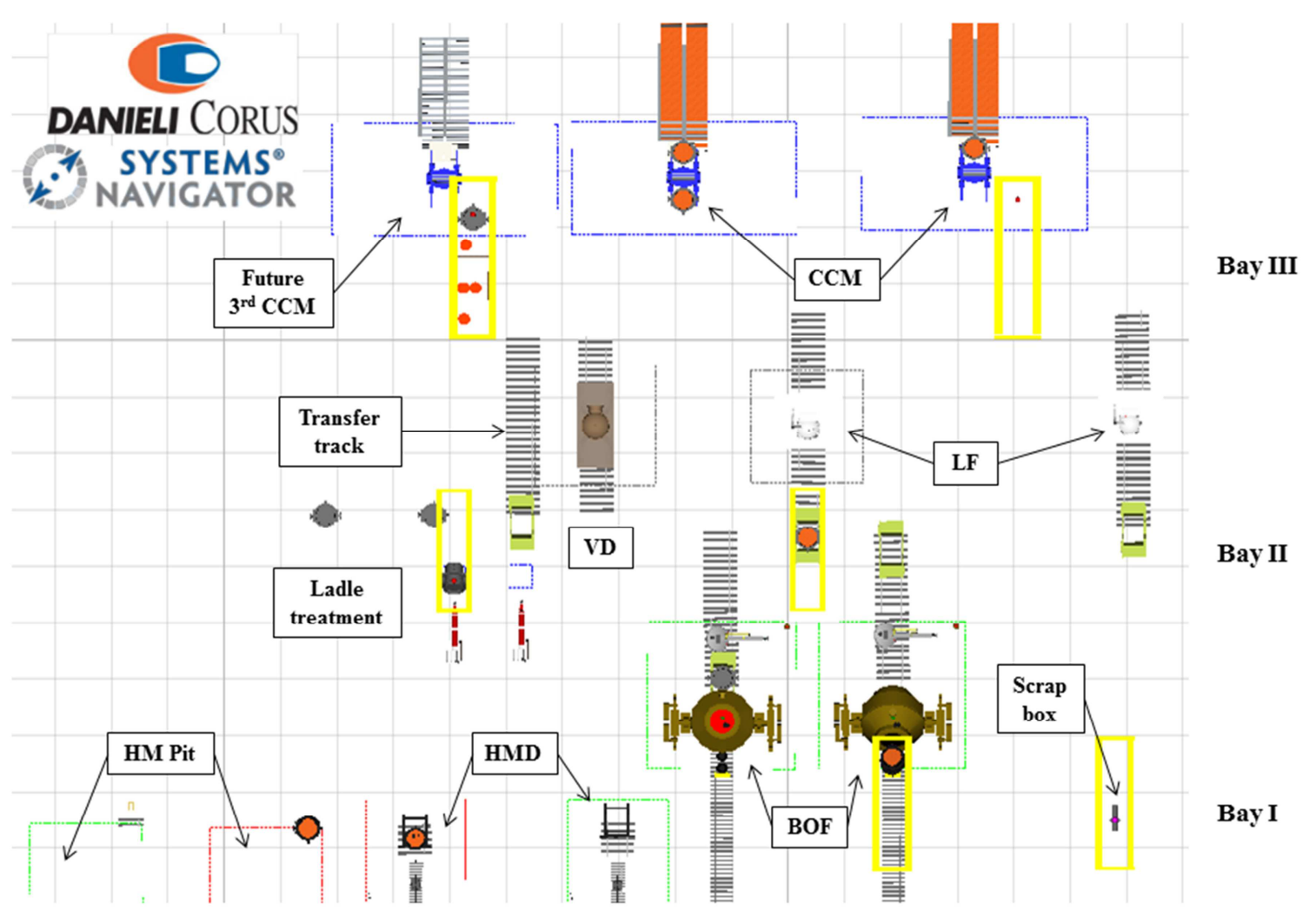

Figure 2. Layout of the fictive plant in the SPM.

The base case simulation resulted in an annual steel production of 2.79 million tons. Figure 3 shows the Gantt chart of a random production day. The chart clearly shows that the casters are a bottleneck in this plant, since they are running continuously (utilization is $98 \%$ ), while the converters could handle a higher production (utilization is $60 \%$ ).

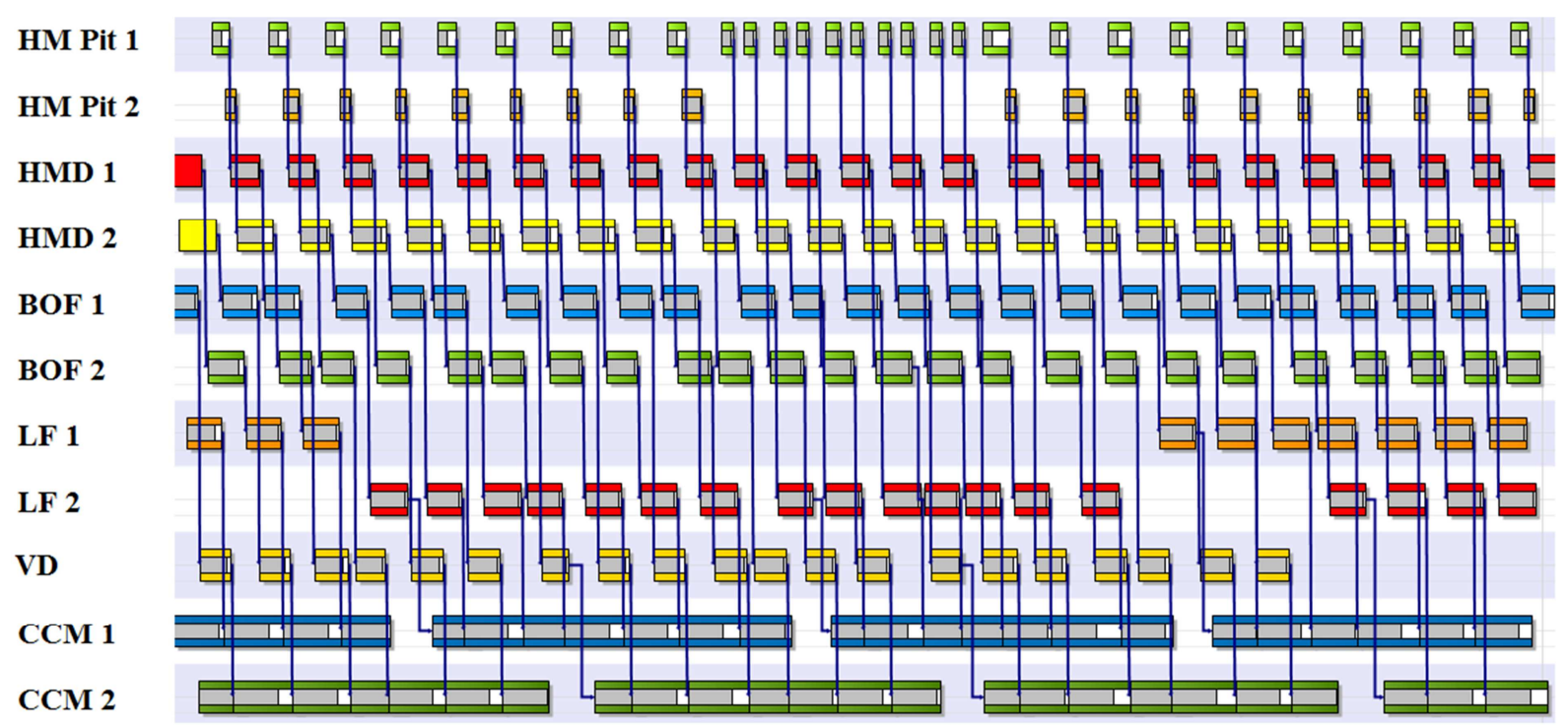

Figure 3. Gantt chart of a random day of the base case simulation. 


\subsection{Third Caster Scenario}

Since both casters are fully utilized, the only way to increase the annual production is to add another caster (if the steel grade mix is not to be changed). However, when a second scenario is run with an additional caster, the total annual production is only 2.82 million tons, which is not a significant increase. The utilization of the casters (preparation, casting and starving) is decreased to $83 \%$, as can be seen in Figure 4.

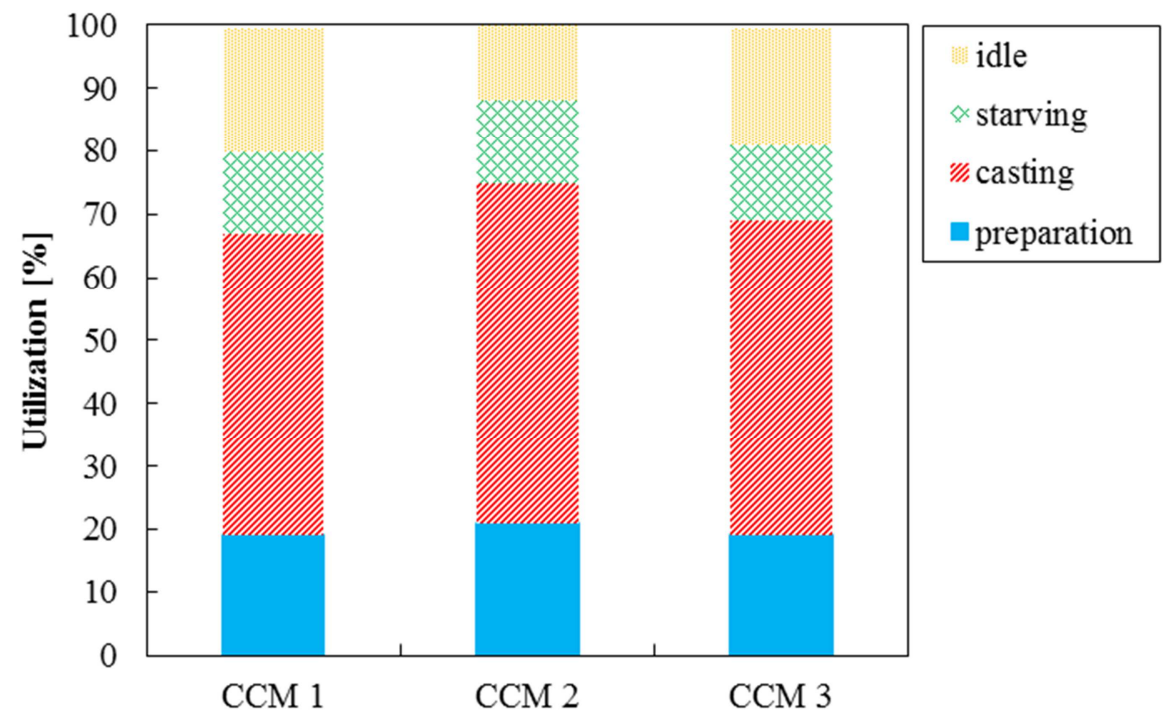

Figure 4. Caster utilization for the third caster scenario.

\subsection{Third HM Ladle Scenario}

Since adding a third caster does not increase the production as desired, the new bottleneck has to be found. When studying the life animation of the 'third caster scenario' or analyzing the utilizations or Gantt charts, the new bottleneck appears to be at Bay I (the hot metal bay). Figure 5 gives the full and empty times of the 2 hot metal ladles for the 'third caster scenario'. It shows that in almost all cases a hot metal ladle is empty for 14 minutes, which is exactly the time it takes to bring a ladle that was emptied back from the converter to the HMP and have it refilled there. The full times of the hot metal ladles are strongly depending on the desulphurization time (which in this example has a normal distribution). 


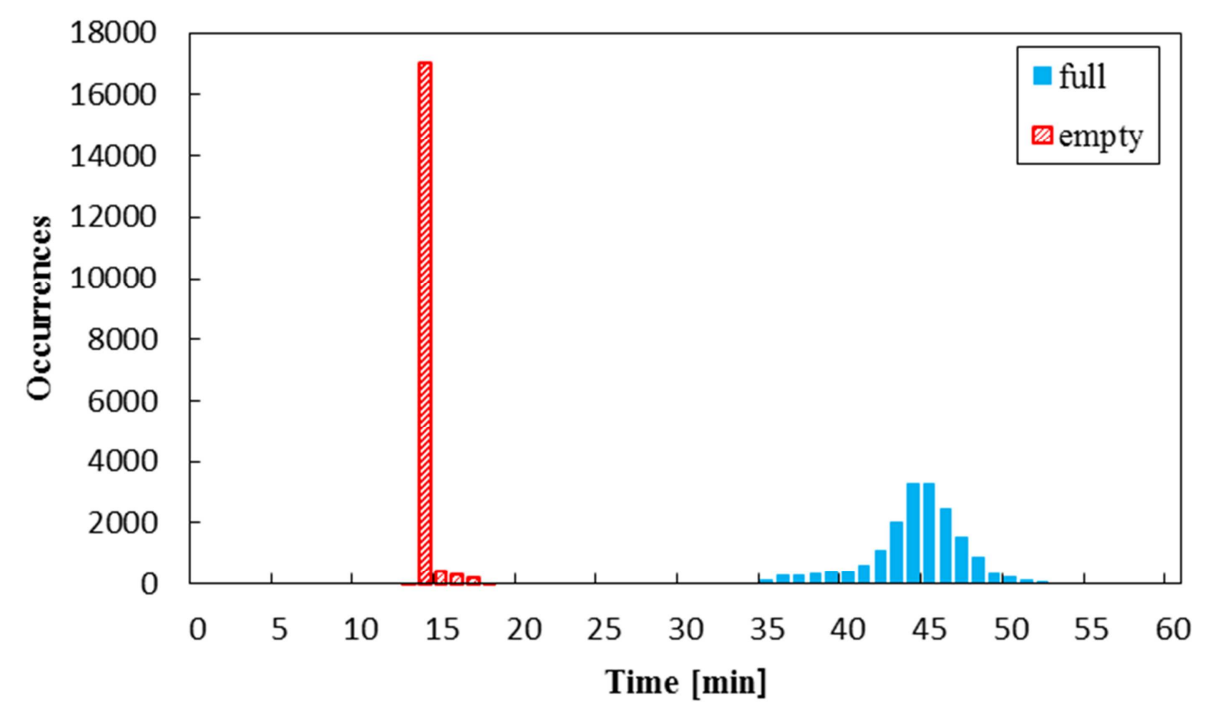

Figure 5. Full and empty times for hot metal ladles for the third caster scenario.

A scenario with a third active hot metal ladle (and 3 casters) has a huge effect on the annual production. The production increases by $32 \%$ to $3.67 \mathrm{Mt} / \mathrm{y}$. The average utilizations of the equipment for the base case scenario compared to the third HM ladle scenario show a better overall utilization, as can be seen in Figure 6. The casters no longer have to run fulltime, while the other (already existing) equipment is utilized more efficient.

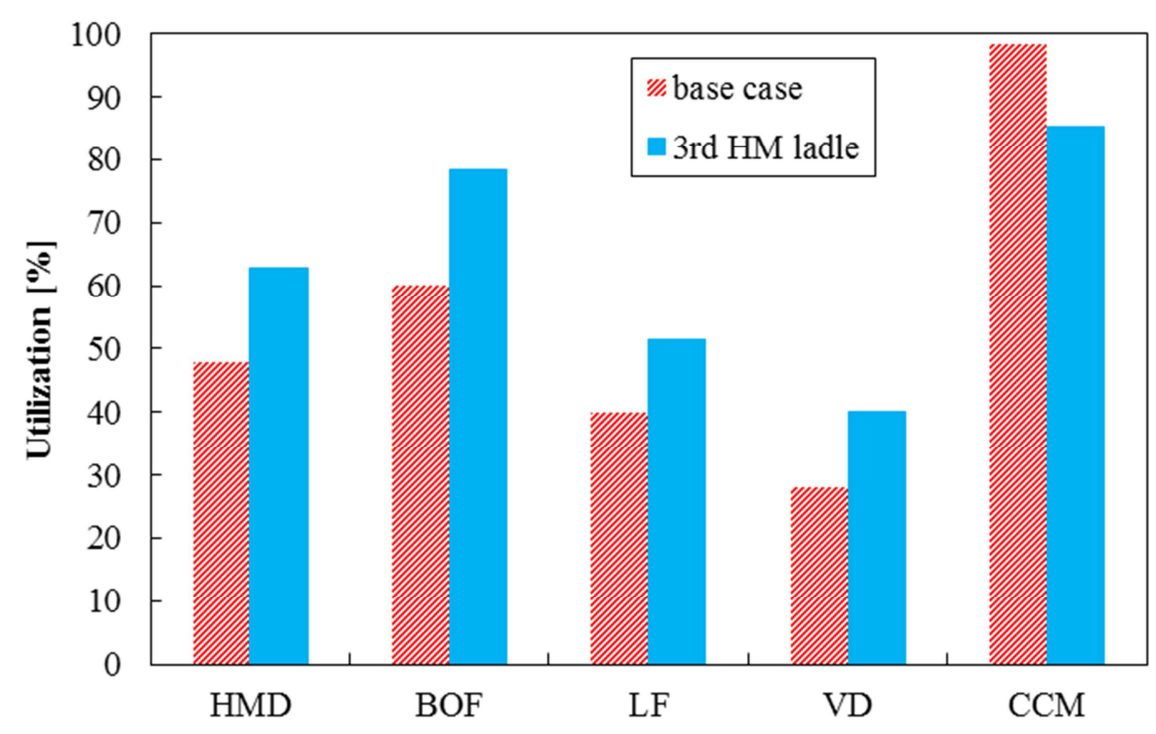

Figure 6. Equipment utilization for the base case scenario compared to the third HM ladle scenario.

Also a scenario with 2 casters and 3 active HM ladles is run, to find out if the third caster was really necessary. However, with this scenario there is no production increase compared to the base case. This proves that the casters were a bottleneck in the base case scenario. 


\subsection{Steel Ladles Optimum}

The steel plant needs to be optimized again when a caster and a HM ladle is added. This optimization is done by running different scenarios with small changes (e.g. different steel grade mix, alternative routing, shorter process times - when and where possible -, more steel ladles, etc.). As an example for this case study the optimal amount of active steel ladles is determined for the new situation. Scenarios with different amounts of steel ladles are run (in the base case 9 active steel ladles were used). Figure 7 gives the results in annual production for the scenarios with different amounts of steel ladles.

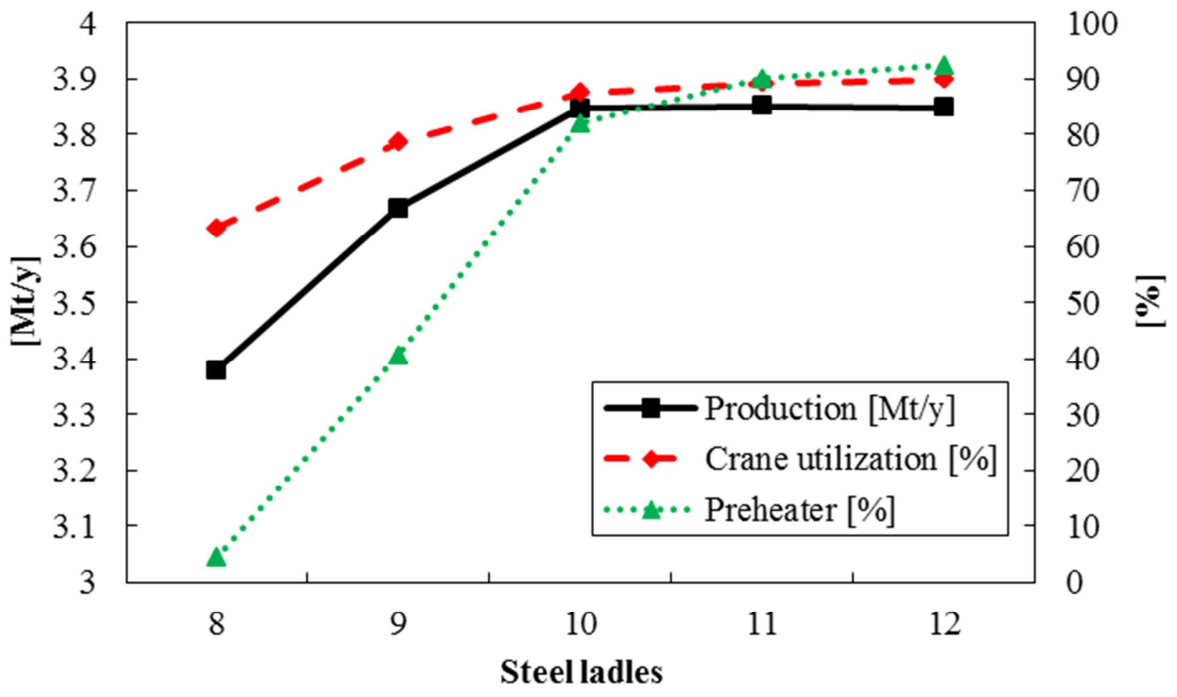

Figure 7. Annual production, utilization of the left crane in Bay II and the percentage of steel ladles that are preheated for scenarios with a different amount of steel ladles.

The optimal production of $3.84 \mathrm{Mt} / \mathrm{y}$ is reached with 10 active steel ladles. More steel ladles do not add significantly to the steel production. When more steel ladles are used the amount of emptied ladles that first go to the preheating station before being refilled again at the converter increases as well. The utilization of the crane that handles the empty steel ladles (the left crane in Bay II) also increases together with the amount of steel ladles since more movements are required. The average preheating time for a steel ladle at the preheater increases from 13 minutes for 8 ladles, via 15 minutes for 10 ladles to 25 minutes for 12 ladles. Using too many steel ladles would therefore result in an unnecessary high usage of the preheating facility, which would lead to an increase in energy consumption. Using the right amount of steel ladles leads to a cost efficient plant practice.

\subsection{Conclusion}

Based on the simulation results of the SPM, the bottlenecks of an existing situation could be identified. When a production increase is desired, a third caster should be added to the steel plant. Also the amount of active HM ladles should be increased from 2 to 3 and the amount of active steel ladles should be increased from 9 to 10 . These improvements would result in an increase of the production from $2.79 \mathrm{Mt} / \mathrm{y}$ to $3.84 \mathrm{Mt} / \mathrm{y}$ (this is $38 \%$ more). 
Note that, since this is a fictive case, the steel plant is not worked out as detailed as an existing plant. This case study should therefore be considered as an example of the SPM's possibilities, rather than as a proof of its accuracy.

\section{CONCLUSION}

The Steel Plant Model is a new logistic simulation model that can be used to identify and solve bottlenecks and logistic issues in a steel plant. This can be both an existing steel plant or a greenfield design. With the SPM different scenarios can easily be tested and compared, enabling the user to find the optimal solutions for logistic issues or to predict the result of any change in the process (from adding a converter to changing the crane priorities or steel grade mix). Thanks to the 3D environment, bottlenecks can easily be visualized with the SPM. The SPM gives an advice in CAPEX and helps optimizing the OPEX.

Furthermore the SPM is unique in taking transportation and its limitations into account in the simulation at a high level of accuracy. The SPM's Smart Cranes are unparalleled in the world of steel plant simulations. This makes the SPM extremely accurate and realistic.

Thanks to the SPM's design it can provide concrete answers and solutions for any steel plant (existing or greenfield) within a short time.

\section{PROSPECT}

Since 2011 the SPM has been in use for various projects with a diversity of layouts and practises. Ever since the library of developed objects and logic is increasing, making the SPM more complete and client-oriented. This results in a higher client satisfaction and faster results.

Currently Danieli Corus and Systems Navigator are developing the Steel Plant Planner (SPP). The SPP takes the SPM to the next level in extending its functionality to a planning tool. The SPP will be able to work with real time plant data and can be used to analyse the impact of different scenarios on a short time base (a day). With the SPP maintenance- and planning-based questions can be evaluated and solved.

\section{REFERENCES}

1 Frank Schrama et al. Steel Plant Model - The Comprehensive Solution for Steel Plant Logistics. $7^{\text {th }}$ European Oxygen Steelmaking Conference, Trinec (Czech Republic). Conference proceedings.

2 Systems Navigator. Scenario Navigator. [internet]. [cited 2015 Mar 9]; Available from: http://scenarionavigator.systemsnavigator.com/. 